\title{
Whose climate and whose ethics? Conceptions of justice in solar geoengineering modelling
}

\author{
Duncan P. McLaren, \\ Lancaster Environment Centre, Lancaster University \\ Library Avenue, Lancaster, LA1 4YQ UK \\ d.mclaren@lancaster.ac.uk
}

\begin{abstract}
The role of underlying assumptions about justice in the construction of climate geoengineering knowledge is explored, based on a review of climate modelling studies focused on stratospheric aerosol injection. Such emerging technologies would create distinctively new climates, closer to the present climate than those resulting from unabated emissions; but with different winners and losers, in part as a result of implications for energy systems. Embedded presuppositions about the nature and practice of modelling are exposed, as are unexplored and narrow utilitarian and distributional conceptions of justice. The implications of these underlying assumptions and values for the discourses of climate geoengineering are considered. It is argued that they obscure the identification and consideration of a range of potential injustices arising in the pursuit of climate geoengineering; and create and reproduce asymmetries in power regarding the discourses and evaluations of climate geoengineering prospects. In particular, optimistic climate geoengineering discourses risk sustaining elite interests in high-carbon energy economies. Some suggestions are offered to improve the design, deployment and interpretation of climate engineering models in trans-disciplinary research so as to mitigate these problems.
\end{abstract}

\section{Highlights}

- geoengineering modeling typically embodies unexplored utilitarian ideas of justice

- geoengineering modeling presumptions and practices may help deter mitigation

- geoengineering models should be used as experimental sandpits not truth-machines

\section{Keywords}

geoengineering, justice, modeling, climate policy, stratospheric aerosol injection (SAI), 


\section{Introduction}

Climate geoengineering is increasingly debated as a response to the problems of climate change and excess carbon emissions from energy systems. In various forms it appears to offer a technical fix that may well deter or delay a transition to clean energy (Markusson et al 2017; Wibeck et al 2015; McLaren 2016a\&b). In this paper I explore ways in which underlying utilitarian and consequentialist presuppositions about justice, expressed in climate modelling practices and results, may contribute to misleading discursive framings of technological optimism regarding the dominant form of solar climate geoengineering: stratospheric aerosol injection. In turn these framings risk stimulating a moral hazard effect in which geoengineering substitutes for mitigation, thus sustaining other negative impacts and injustices of fossil fuel extraction and use.

Climate geoengineering techniques are typically divided into carbon dioxide reduction (CDR) and solar radiation management (SRM). CDR involves removing greenhouse gases from the atmosphere, and, as a technical fix, promises future recovery of current emissions. CDR is not considered further here, but is already embedded in climate pathways models as a means to square carbon budgets to meet particular temperature targets (Fuss et al 2014; Anderson 2015; Peters and Geden 2017). SRM reduces the proportion of the sun's heat captured in the earth system, typically by reflecting more sunlight. Stratospheric aerosol injection (SAI), which dominates the geoengineering literature (Linnér and Wibeck 2015), would reflect sunlight by dispersing small particulates into the stratosphere using aircraft, artillery or a balloon-lofted pipe, and thus reduce global temperatures through the same basic mechanism as occurs with large volcanic eruptions.

Although such interventions are yet little more than technological imaginaries and their future evolution as co-constitutive parts of socio-technical systems largely unknowable (Stilgoe 2015), increasingly detailed climate modelling work using Global Circulation Models (GCMs) has begun to sketch possible distributional climatic consequences of such imagined SRM interventions, treating them as concrete objects. As in the case of CDR, here the models also co-constitute these technological imaginaries, with very limited scope for empirical validation, and do so in a charged policy space in which the politics of climate denial largely prevents constructive questioning of modelling and its assumptions. This means that climate modellers arguably bear an elevated responsibility to consider the possible social consequences of their work. This paper seeks to suggest ways in which modellers, other climate researchers and policy makers could act reflexively to enhance contributions to justice in climate policy.

To fully investigate the justice implications of climate geoengineering means considering how it might affect people across plural dimensions of distribution, vulnerability, capability, structural inequalities, procedure, recognition, and restoration or correction (Jasanoff 2003; Mamo and Fishman 2013; Schlosberg 2007, 2012; Shrader-Frechette 2002; Sen 2009; Jenkins et al 2016; Hourdequin 2016). Climate change is not simply a justice issue because its effects are spatially and temporally uneven, as often presumed in the climate geoengineering modelling literature, it is also a justice issue because vulnerability to those effects is also uneven, and tightly inter-linked with existing economic, political and cultural injustices and power imbalances, in which the victims are often poorly recognized, their rights not respected and compensation resisted (Athanasiou and Baer 2002; Schlosberg 2012; Shue 2014; Armstrong 2017; McLaren 2017). Moreover, responses to climate 
change are also tightly interwoven with energy systems and their justice implications (Sovacool et al 2015; Jenkins et al 2016). Geoengineering may imply significant energy demands, impact differentially on different energy sources, or promise to reduce climate risk while allowing continued exploitation of fossil fuels (McLaren 2016a, b). It cannot be assumed simply that a reduction in overall climate risks will necessarily enhance justice. It is important to ask who will lose or gain, where, when, and in what respects.

As outlined below, modelling of SAI predominantly suggests that it could - at a gross, global scale significantly reduce, or at least mask, the impacts of unabated climate change. And, given that existing and likely impacts of climate change are disproportionately borne by the poor and disadvantaged, it might be argued that the deployment of SAI would enhance justice (Horton and Keith 2016). But there are also reasons to significantly qualify or even dismiss such a claim. First SAI is not a perfect substitute for mitigation (Keith 2013), and the distribution of residual and novel impacts could be important for an unknown proportion of the poor and disadvantaged. Second, insofar as SAl acts as a substitute for, or deters, mitigation (McLaren 2016a; Morrow 2014b), any negative side-effects of SAI would be magnified, and any co-benefits of mitigation reduced.

Moreover any failure of SAI in practice would then result in more severe climate impacts than had mitigation not been deterred (Baatz 2016), although the justice implications of this would depend to some extent on whose emissions had continued. In particular, if SAI permitted greater use of fossil energy in poor Southern countries, it might enhance energy justice, but if it rather sustained energy rich lifestyles in the global North, the opposite would result. Third, justice arguably has richer and plural dimensions - beyond those defined in terms of consequential harms and benefits (Sen 2009) in which climate risk may be a poor proxy for justice. In this paper I explore how the presumptions and practices of climate geoengineering modelling tend to downplay such qualifications, thus sustaining a discourse of climate geoengineering that despite being cautious, is nonetheless inappropriately rosy.

\section{The significance of models and modelling}

Before discussing the detailed findings and implications of climate geoengineering modelling, it is necessary to briefly consider the status and purpose of such scientific models. Researchers have developed increasingly sophisticated computer models - using both physical principles and historical climate data - in efforts to predict and understand the implications of rising greenhouse gas concentrations (Edwards 2011; Flato 2011; Curry and Webster 2011). Despite substantial uncertainties, climate models have contributed to a substantial improvement in our understanding of the relationships between energy systems and climate change. In the context of climate engineering, they provide illuminating opportunities to simulate - and experiment with - alternative conditions, scenarios and pathways in ways that are simply impossible empirically. This implies a responsibility to communicate assumptions and limitations carefully and clearly, but in the context of bitterly contested climate politics such caveats are rarely heard, even when offered. As a result climate models have been described as 'seductive simulations' (Lahsen 2005) and 'technologies of hubris,' offering a misplaced modernist concept of management and control that pre-empts political discussion (Jasanoff 2003). They are embedded in an administrative risk-management social imaginary (Groves 2014) which depoliticizes climate change in critical ways (Swyngedouw 2010). They as act as gatekeepers of claims about climate change (Sundberg 2007) and as boundary- 
ordering devices between science and authority that sideline uncertainty (Shackley and Wynne 1996). As a result modelling co-constitutes particular sorts of worlds. As in the case of energy system research and models (Sovacool et al 2015), climate models tend to constitute technologically-framed worlds, rather than social ones. Nonetheless, such models are now being deployed and further refined technically to explore the potential implications of climate geoengineering. It must be stressed at this point that the constructivist effects of modelling are not the intentional product of modellers, but an emergent result of the co-production of models, technologies, discourses, imaginaries and institutions in this space. This makes for a difficult epistemological and methodological challenge. Empirical investigation of the beliefs and intents of modellers (for instance through qualitative interviews), although potentially useful, could not reveal and explain such outcomes. Here a critical, discursive review of the modelling literature is applied in an effort to begin to expose the co-productive relations between models and values which structure climatic imaginaries. An analysis of the outputs of practices (the modelling literature) is an essential first step in exposing and understanding presumptions arising in the social imaginary which shapes such practices. At times I will speculate as to modellers' motivations, but the central case I seek to make is that their modelling practices embody and construct particular ethics and values regardless of modellers' intentions.

Because the future state of the climate and the effectiveness of climate policy are complex and indeterminate, the status that models are granted critically structures the interpretation of scientific evidence. Models may be treated in diverse ways across a spectrum from 'truth machines', to more honest 'sandpits' for experimentation (Galarraga and Szerszynski 2012) or 'props in games of makebelieve' (Toon 2010). Audiences for models must 'play the game', which makes modelling a social activity (Corry 2015). So the use and interpretation of models depends heavily on a shared language, vocabulary and grammar and is thus co-constituted with disciplinary discourses. Wiertz (2016), suggests that model-based climate geoengineering research shapes social and political expectations around technologies, whilst underlying presumptions, such as the models' reliance on a "figure of a single rational decision maker who designs and evaluates the performance of the technology" (p.454) remain unquestioned. Wiertz challenges us to question the "relation between model-based and social visions of climate futures" and the ethical and political questions raised by the practice of climate geoengineering modelling. Modellers often appear reticent to engage directly with such questions - which admittedly extend beyond the quantitative evidence base provided by modelling within the scientific literature (see table 1). Yet in this very unwillingness, they tend to import unquestioned presumptions from the dominant social imaginary (Groves 2014) into their practices and interpretations, which can in turn be exposed by qualitative discursive analysis.

This is a space in which scholarship is sparse. There is work on the ethics of the technologies and policies of climate engineering (Gardiner 2010; Morrow 2014; Svoboda 2016), some of which engages explicitly with economic modelling using Integrated Assessment Models (notably Hansson 2014). Examinations of climate geoengineering from a science and technology studies orientation seek to open up framings and narratives to assist with the evaluation of climate geoengineering proposals (Bellamy 2016; Cairns and Stirling 2014) but this work tends to lack a clear normative dimension with respect to justice (Mamo and Fishman 2013). Finally, there are some researchers who use or examine modelling processes and seek to modify and weight outcomes in an effort to represent ethical or justice concerns (eg Moreno Cruz et al 2012; Ferraro et al 2014). This latter 
literature forms part of the papers examined here, and as will be seen, the epistemology involved tends to privilege certain forms of ethical judgement and certain values of justice.

This paper focuses therefore on exploring and unpacking both explicit and hidden assumptions about justice. These presumptions arise at several levels: first in the modellers' interpretation of their models' outputs; second in the modelling practices; and third in values or conceptions of justice which researchers (typically unquestioningly) import into their modelling and analysis. The first part of the paper addresses each of these levels in turn, based on a focused review of the modelling literature. The second part of the paper then discusses how these interpretations, practices and values relate to discourses and framings of climate geoengineering with respect to risk, vulnerability and power, and considers the relevance of plural and relational dimensions of justice drawn from the environmental justice and science and technology studies literatures. This analysis is informed both by the literature, and by participant observation in major climate geoengineering conferences, symposia and summer schools. ${ }^{(1)}$ Further work might helpfully elaborate this step by conducting formal qualitative interviews or deliberative engagements with modellers themselves, seeking to better understand and explore their motivations and ideas of justice. Nonetheless, simply putting the different literatures and discourses into dialogue is revealing and suggestive. Finally the paper draws conclusions regarding the possible implications of climate geoengineering for climate justice.

\section{Representations of justice in modelling of SRM}

Based on a broad literature review, involving iterated searches of Scopus and Web of Science, using the terms 'geoengineering' or 'solar radiation management' plus 'regional effects', 'regional inequalities' or 'regional disparities', I identified 11 key studies prior to 2016 that address spatial distributional implications (at a regional scale, rather than just global impacts). Although the initial search returned around 70 papers in total, I eliminated those that did not report climate system modelling, those that focused only on localised applications (eg protection of coral reefs), and those which did not consider SAI (although some simulate SAI by adjusting the solar constant). The remaining 11 papers are listed in table 1 , and considered in this section, supported by references to other, often more fundamental modelling and non-model-based studies whose outputs are helpful to understanding ways in which climate geoengineering might impact on justice. The database searches were supplemented by on-going monitoring of geo-engineering list-servers (the geoengineering google group, and the Kiel Earth Institute's climate engineering newsletter). The resultant set of papers may not be entirely comprehensive, but it is representative of the field, and of the evolution of research into the likely distributed impacts of SAI. The researchers and institutions involved go beyond what Kintish (2010) called the 'geoclique' although that group is strongly represented. Almost all of the papers identified have been widely cited (see table 1 for frequencies).

In this section I first outline the key findings of modelling studies regarding the potential distributional effects of SAI, and discuss how they have been interpreted, particularly regarding consideration of winners and losers. I then turn to issues arising in the practices of modelling, with a focus on counterfactuals, uncertainties and vulnerability. Throughout, I quote directly from the modelling studies identified through the literature review to help illustrate relevant presumptions 
and practices. I conclude the section with a brief summary of the concepts of justice revealed by the modelling.

\section{Model outputs and their interpretation}

Much of what scientists understand of the likely implications of SAI SRM comes from modelling studies (see Table 1, which summarises the key findings outlined in this section). The last decade has seen a rapid increase in climate geoengineering modelling, with increasingly sophisticated models, multiple model runs utilising increasing computer power, and in recent years, efforts to compare multiple models as part of the geoengineering model intercomparison project (GeoMIP) (Kravitz el al 2014; Yu et al 2015; Schmidt et al 2012; Niemeier et al 2013). Simple models simply simulate a reduction in incoming solar radiation, while more sophisticated ones directly model stratospheric distributions of aerosols, providing more detail of dynamic and distributed effects. There is broad consensus in the modelling community (dominated by US, UK and German scientists), over the largescale effects of SAI, but still significant uncertainty (and even disagreement) over several parameters of significance for regional impacts, such as cloud effects or ocean circulation (Driscoll et al 2012; Schmidt et al 2012; Niemeier et al 2013; Curry et al 2014; McCusker et al 2015). Different models and even different runs tend to suggest different results - exposing significant inter-model variation (Yu at al 2015).

\section{Latitudes and hemispheres, temperature and precipitation}

Modelling suggests that even uniformly distributed reductions in solar radiation would have distributional consequences. Such SRM could broadly cool the planet (Kravitz et al 2014; Irvine et al 2010; Robock et al 2008), but the temperature offsets achievable through uniform global SAl are expected to be latitudinally distributed, with "significant cooling of the tropics [but substantial residual] warming of high latitudes and related sea ice reduction" (Lunt et al 2008:1; also Schmidt et al 2012; MacMartin, Keith et al, 2013). Effects on precipitation would be more diverse, with overcompensation for the effects of climate forcings in some regions and undercompensation in others (Robock et al 2008; Schmidt et al 2012; Curry et al 2014; Yu et al 2015). Changes in precipitation may be "quite small relative to interannual variability at the regional scale" (Bala et al 2008:7668) but still significant. Schmidt et al (2012) found that regional precipitation changes may exceed those under unmitigated climate change, a finding supported by Ferraro et al (2014). Moreover the variations would be inconsistent. For instance, "simulated temperature and precipitation in large regions such as China and India vary significantly with different trajectories for [SRM], and they diverge from historical baselines in different directions" (Ricke et al 2010:537). Modelled precipitation divergences are more severe for SAI than solar dimming (Niemeier et al 2013; Ferraro et al 2014). Ferraro et al find four times more area and population at risk of substantial increases in precipitation under SAI than solar dimming. Aerosols also have dynamic effects on atmospheric, and consequentially oceanic circulation. In the southern hemisphere, SAI might even warm deep ocean currents around Antarctica, a key driver of ice-sheet collapse and sealevel rise (McCusker et al 2015).

Modelling a larger aerosol loading in polar latitudes appears to compensate for the latitudinal distribution of temperature effects but not the ocean dynamics. Moreover it also "tends to degrade the degree to which the hydrological cycle is restored" (Ban-Weiss and Caldeira 2010:1). And even 
fully masking average temperature change is predicted to only reduce, but not eliminate changes in weather extremes (Curry et al 2014). Nor would it halt sea-level rise: to do that, as Irvine et al (2012) show, would require an average aerosol loading that would more than compensate for temperature rise. ${ }^{(2)}$

Potential distributional consequences from precipitation changes are not insignificant. Early modelling by Robock et al (2008) suggested that both tropical and Arctic SAI would result in " $a$ weakening of the African and Asian summer monsoon circulation, an effect found previously from high-latitude volcanic eruptions" (p.8). However, more recent modelling indicates less extreme implications (Schmidt et al 2012; Tilmes et al 2013). Nonetheless, MacMartin, Keith et al (2013) advocate seasonal distribution of SAI interventions to ameliorate the risk of negative effects on precipitation in monsoon regions. If SAI were heavily biased to one hemisphere the implications could be more dramatic. Haywood et al (2013:660) find that: "large asymmetric stratospheric aerosol loadings concentrated in the Northern Hemisphere are a harbinger of Sahelian drought whereas those concentrated in the Southern Hemisphere induce a greening of the Sahel." In a similar vein, Jones et al (2017) find that Southern hemisphere SAI would exacerbate North Atlantic tropical cyclone frequency relative to global SAI, while Northern hemisphere SAI would depress it. Yet hemispherically asymmetric SRM intervention might be deliberate - not just a modelling fiction. Several authors have suggested or examined Arctic dominated SRM (eg Lunt et al 2008; Irvine et al 2010; MacMartin, Keith et al 2013). Moreover, the only advocates for immediate deployment of SAI argue for Arctic deployment to prevent loss of sea ice and subsequent methane feedbacks. ${ }^{(3)}$ Such an asymmetric deployment would need to be substantial. Tilmes et al (2014) estimate that the SRM forcing required to retain summer sea ice would be four times greater in a polar deployment than in a global one.

\section{Novel climates and modulated SRM}

SRM could not simultaneously compensate everywhere for changes in both precipitation and temperature. Climate geoengineering modellers have responded to this in two related ways: by seeking to assess the scale of 'residual' effects, and by modifying the scenarios they model in an effort to minimize those residuals. Moreno Cruz et al (2012) developed a 'residual climate response' approach that combines deviations in temperature and precipitation. Irvine et al (2010) quantify the extent of 'novel climates'. And Ferraro et al (2014) develop a risk ratio to describe the likelihood of problematic novel climatic conditions. Modellers have explored modulating the levels and spatial and temporal distributions of SAI interventions. Yet, as explored below, the findings of such modelling are often interpreted and reported in ways that may underplay the implications of remaining distributional problems.

Several studies have modelled levels of SAI that only partially mask temperature changes, to reduce the extent of harmful overcompensating precipitation changes. For example, Moreno-Cruz et al (2012) model returning an unabated $2 x \mathrm{CO}_{2} 2030$ climate to 1990 s temperatures, and report that separately each factor can be almost perfectly corrected (97-99\%). However, their abstract's optimistic interpretation that "while inequalities in the effectiveness of SRM are important, they may not be as severe as it is often assumed" (p.649) is rather contradicted in the body of the paper. This notes that: "Compensation is harder when one tries to optimize for both temperature and 
precipitation at once. ... the SRM scheme that minimizes ... precipitation changes compensates for only $70 \%$ of ... temperature changes" (p.651).

And this remaining trade-off could have profound distributional consequences. Moreno-Cruz et al also state that: "the first region to reach its optimum as we incrementally increase SRM is Western Africa ... [Where] the optimal amount of SRM ... is 78\% of the [full amount] ... An increase in the level of SRM beyond this point makes Western Africa worse-off' (p.661). Moreno-Cruz et al estimate that $78 \%$ of full SRM would compensate for $56 \%$ of global damages from climate warming. But they choose not to draw out the disturbing implication that to optimise for any other region - the mainland USA for example - or to seek to mask a higher proportion of global damages, would therefore make things relatively worse for some of the poorest countries in the world, when comparing it with SRM optimized for Western Africa.

Some subsequent researchers have adopted a similar method of estimating residual climate responses (eg MacMartin et al 2014; Yu et al 2015). Yu et al, however, highlight how "large acrossmodel variation in the treatment of key geoengineering processes (such as stratospheric aerosols) and the quantification of damage caused by climate change creates significant uncertainties in any strategies to achieve optimal compensation effectiveness across different regions" (p.10). Others have sought to tame and quantify regional disparities arising from SAl by developing a concept of 'novel climate', with the apparent ambition of modulating their modelled interventions so as to minimise the incidence of such novel climates. However this has highly problematic consequences for the framing of the climate justice problem. Irvine et al (2010) define a novel climate as "a climatic state, measured by either surface temperature or rainfall (annual or seasonal), that lies outside the continuum of climatic states bounded by the preindustrial and an unmitigated $\left(4 x \mathrm{CO}_{2}\right)$ greenhouse" (p.5). Their results show 'novel conditions' - primarily in precipitation, over up to $28-45 \%$ of the earth (from SAI designed to reverse $70-80 \%$ of the warming arising from $4 \times \mathrm{xO}_{2}$ (Irvine et al, 2010: figure $3 b)$ ). To interpret this, as the authors do, as limiting novel climate states to 'only a small fraction' of the earth (p6), seems overly optimistic. Furthermore, in Irvine et al's results, higher levels of SAI generate an even wider spread of both novel precipitation and temperature regimes. Yet their definition of novelty already normalises extreme climate change. A $4 \mathrm{xCO}_{2}$ climate is massively beyond human experience. If it is 'novelty' that signals the potential for significant harmful regional changes, but a $4 \times \mathrm{CO}_{2}$ greenhouse is not considered novel, this frames the associated climate impacts of business as usual as more acceptable, so the historic injustices embedded in their causation are more easily overlooked.

Even if SAI could be restrained to reduce disruptive effects on precipitation, it appears that there would still be significant areas with novel and potentially harmful climatic conditions, and many different or new winners and losers. Model inter-comparison appears to confirm this. Kravitz et al (2014) model SAI restricted to compensate only $85 \%$ of the difference from preindustrial temperatures, and suggest that, in a world divided into 22 regions, this delivers regional temperatures closer to preindustrial levels than to a $4 \times \mathrm{xO}_{2}$ world "for all regions and all models" (p.1). However: "in all but one model, there is at least one region for which no amount of solar reduction can restore precipitation toward its preindustrial value" (p.1). Moreover, if only precipitation were considered significant, "11 of the 12 models show the [optimum] amount of geoengineering determined by the Pareto criterion to be zero"(p.4) and for nine of the 22 regions at least one model shows precipitation changes that exacerbate, rather than ameliorate, the effects of 
climate change. Yet again, the interpretation of this work is given an optimistic spin. By weighting temperature and precipitation effects equally in their overall evaluation these authors conclude that SAI would create 'no new winners and losers'. In reality, though, such an equal weighting is misleading: some regions and groups would be far more vulnerable to temperature impacts than precipitation changes, and vice versa.

Ferraro et al (2014) are less optimistic. Using a somewhat different method of assessing novelty (a risk ratio, estimating the risk of experiencing a year in which the mean surface temperature or precipitation is outside one standard deviation of the current interannual variability), they find over $40 \%$ of the Earth's surface experiencing increased risk of substantial precipitation change under $4 \times \mathrm{CO}_{2}$ plus SAI than under elevated $\mathrm{CO}_{2}$ alone. Some advocates of SRM research imply that optimism is justified by the potential for modulating the level of, and/or targeting the timing and locations of SAI (Irvine et al 2010; MacMartin et al 2014; Moreno Cruz et al 2012; Curry et al 2014) ${ }^{(4)}$ Niemeier et al (2013) suggest that a global balancing of transient forcings with SAI may be possible, but raise some practical caveats. On the other hand, MacMartin, Keith et al (2013) introduce the possibility of not only varying the global level, but also fine-tuning both the latitudinal and seasonal distribution of SAI. They report that with such modulation: "residual temperature and precipitation changes in the worst-off region can be reduced by 30\% relative to uniform solar reduction" (p.365). But such benefits may be as imaginary as the technologies involved: they depend strongly on assumptions of controllability and uniform vulnerability, as discussed in the next section.

Overall, therefore, the modelling appears to show that, in terms of global average effects, masking greenhouse forcings with SAI would probably leave most places better off than under unabated climate change. Yet SAI is not a perfect substitute for mitigation, nor can it restore previous climates. ${ }^{(5)}$ SAl would reconfigure, or even make new climates, with serious implications for climate justice that must be considered in climate policy. There would be dynamic regional and temporal patterns of impact - at scales at which the model uncertainties are much greater - that could expose particular populations, across significant proportions of the world, to continued or enhanced risk. A significant minority might suffer undesirable shifts in precipitation regimes, only some of which might be mitigated somewhat by more targeted and refined application of SAI, even if that were to prove practical. While early modelling studies arguably exaggerated the possible implications of such impacts, much recent work appears to downplay them. The next section turns to some of the modelling practices that would appear to structure such optimistic findings and interpretations.

\section{The implications of model design and assumptions}

Modellers themselves have highlighted the way in which simulating SAI by reducing solar irradiance, rather than by introducing aerosols appears to better counter greenhouse gas forcings (Niemeier et al 2013; Ferraro et al 2014; Yu et al 2015). But this is only one distorting practice, and in some respects a superficial one, easily rectified. Here I focus in on three key more deep-rooted and pervasive features of the modelling practices that appear to help construct the optimistic narratives: use of inappropriate counterfactuals; overconfidence in the predictability and controllability of SAI; and largely ignoring variation in vulnerability. Not only do these features tend to over-simplify assessments and focus attention on specific dimensions of justice, while framing out others, but their effects also appear to structure and even pre-condition the findings that suggest that SRM 
could be just. This is not to suggest that models should be expanded to try to better incorporate justice, rather that presumptions about justice must be unpacked to create opportunities to explore and experiment with the implications of alternative assumptions and conceptions of justice.

\section{Extreme counterfactuals, catastrophism and the clean sheet}

Modelling studies typically contrast high greenhouse gas worlds (in a majority of cases, a $4 \times \mathrm{xO}_{2}$ greenhouse) in the presence or absence of SRM, rather than contrasting the outcomes of SRM with either preindustrial climates or the outcomes of partial mitigation (see Table 1). This almost universal choice of counterfactual appears to reflect a common belief that adequate mitigation has become politically or practically implausible (e.g. Keith 2013). Mitigation effort may indeed be currently inadequate to avoid dangerous climate change, and it might even be true that no practical rate of improvement in mitigation could avert dangerous climate change; but it is unreasonable to imply that no progress will be made to reverse emissions growth even as impacts become severe and immediate.

Using a counterfactual of unabated climate change makes modelling results easier to identify and the effects of different factors easier to isolate, but it also exacerbates the potential for consideration of climate geoengineering to distract attention from other responses - the so called 'moral hazard' (Gardiner 2010; Morrow 2014b; Corner and Pidgeon 2014; McLaren 2016a). In its political form, moral hazard suggests decision makers may be tempted to avoid controversial or costly decisions to mitigate in favour of hypothetical future SRM. This would exacerbate risks for future generations if SAI failed to work as expected, or were prevented or halted by political disagreement. Inappropriate counterfactuals unintentionally foster a misleading impression that SRM is a direct alternative to mitigation (despite apparently well-intentioned assertions to the contrary by most researchers). Such counterfactuals also make SAI more palatable, because in comparisons with unabated climate change, any potential negative disparities arising from SAI appear less significant if the alternative appears to be a climate catastrophe. As shown above, such comparison has already restricted the identification of 'novel' or 'harmful' climates in some modelling work.

Moreover, this framing of the distributional consequences of unabated climate change presents them as virtually inevitable, if unintended, and thus in certain respects as of less moral consequence than if they were recognised as the result of active human agency (Morrow 2014a). This is not to claim that SRM modellers are unconcerned by climate injustice, rather that the construction of their models incidentally deflects attention from the historic causes of that injustice and the potential for its attempted rectification by accelerated mitigation. The more the framing of the models reinforces the claim that it is physically impractical and politically unrealistic to avoid a high greenhouse gas world (McLaren 2016b), and the more focus is drawn to technological means of avoiding the extremes of climate impacts, the less attention we can expect to be paid to any moral obligations arising from historic emissions. In this way the models reflect a sort of 'clean sheet' analysis that looks only forward, and in which past responsibility for emissions, and any form of corrective justice, is not taken into account. 


\section{Uncertainty and control}

As seen in the quotes so far, the language of modelling is replete with claims that SAI 'can', or 'will' deliver certain outcomes, or could be managed, modulated, targeted, or optimised. However, not only are these claims products only of modelling, not empirical experiments, they also ignore the practicalities of delivery and control. Bellamy (2016), following Stirling (2003), criticises climate geoengineering appraisals generally for a narrow focus on risk and a failure to recognise uncertainties. The modelling literature largely assumes away uncertainties in three spheres: in the technologies for SAl, within the models themselves, and in the monitoring and control mechanisms that would connect them (see Table 1). Such uncertainties may be critical to judgements about the desirability of SAI, as seen, for example in the caveats raised by most of the modellers who have sought to simulate aerosol injection directly, rather than by simulating reduced solar irradiance. Moreover, if SAI might not be practically realisable or controllable, then any deterrent or delay to mitigation becomes much more risky.

In the first sphere, even the most optimistic researchers concede significant 'non-trivial' uncertainties that demand further research into SAI technologies (Keith 2013) while other natural and social scientists suggest the technical challenges may be so great that a practical, cost-effective and socially and politically acceptable system may never be feasible (Hunt cited in Koplewitz 2015; Stilgoe 2015). In other words, technologies for precise and controllable delivery of aerosols imagined in the modelling might remain imaginary, called into being only by the parameters and functioning of the models (Wiertz 2016). This offers little confidence that SAI could be targeted effectively. Yet MacMartin, Keith et al (2013) largely dismiss the question. They confess: "We do not address how one might achieve the desired forcing distributions" (p.367), but argue that "Although these variations may be difficult to achieve in practice, it is premature to presume today what variations might ultimately be achievable ... [future] engineered particles or space-based systems might enable more control over the distribution of solar reduction" (p.366).

Even if the physical challenges can be surmounted, managed delivery would rely on models that permit us reasonably to predict the climate outcomes of any climate geoengineering intervention, and control systems that would deliver the desired effects, in the face of huge lags and complexity in feedbacks (also attributed using models). The uncertainties involved in this second sphere are also substantial. To confidently predict the sort of detail reported above would require models that accurately reflect complex connections between different climatic regions, yet even the interactions between hemispheres and latitudes are only now emerging (Haywood et al 2013; Jones et al 2017). For example, climate models generally fail to capture several significant dynamic responses in the northern hemisphere observed following tropical volcanic eruptions (Driscoll et al 2012) and often miss dynamic effects of aerosols on ocean circulation in the southern hemisphere (McCusker et al 2015). This may not cast doubt on the potential for SAI to cool the climate generally, but must give researchers pause in claiming that they can predict regional effects adequately.

When considering the uncertainty in models, the distinctions between runs, ensembles, and controlled inter-model comparisons must be acknowledged. Individual runs have inherent variability. Ensembles can embody consistent biases. Inter-comparison studies encompass a broader range of possible outcomes, but are still constrained by the selection of scenarios, and can establish dominant framings and path dependencies (Sundberg 2011). Although climate models can clearly be 
improved further, they will inevitably remain inherently incomplete and uncertain (Curry and Webster 2011; Stilgoe 2015). Moreover, seeking to reduce variations in modelled climatic responses may distract attention disproportionately from the implications of social, economic, cultural and political vulnerabilities, considered in the next section.

In the third sphere, technical controllability, the literature is sparse. MacMartin, Kravitz et al (2013) and MacMartin et al (2014) find that cybernetic feedback could be used to control model temperature outputs, even with limited understanding and a crude model. However they note fundamental trade-offs, such that managing uncertainty risks amplifying variability. MacMartin, Kravitz et al's approach is essentially technocratic, although they do acknowledge that technical requirements for rapid feedback control "may be incompatible with ... a stable decision-making process that is able to gain legitimacy" (2013:255). Jackson et al (2015) report an experimental approach that begins to explore such problems, using two layers of modelling and iteration of interventions in annual rounds, targeting Arctic sea-ice retention. The researchers were able to establish control over the model (after about a decade), but their experience suggests that in reality, with political and social influences as well as technical ones, the controllability of SRM remains highly uncertain. And even if control were to prove plausible, it would raise serious procedural justice questions regarding how all those affected might participate in governance of a managed climate.

At the present state of knowledge, moreover, SAI would appear to involve a wider range and scale of uncertainties than mitigation (although MacMartin et al (2015) find that the uncertainties of climate change and solar geoengineering appear to be at least partly offsetting, rather than additive). These uncertainties mean that climate impacts may be more evenly or unevenly distributed than the models imply. But, equally critically, the level of uncertainty itself is significant for justice in the same way as climate variability. Groups with greater capabilities, strong social capital, and majority recognition are simply less vulnerable to uncertainty about future climates than those with weak capabilities, limited social capital or suffering misrecognition (McLaren 2017).

\section{Variation in vulnerability}

Other features of the modelling methodologies and practices - especially the implicit characterization of affected populations - also shape how justice implications are revealed and interpreted. Inappropriate or limited criteria, aggregation and implicit assumptions of uniform preferences and values can all act to frame out important dimensions and questions of vulnerability. Vulnerability shapes experiences of extreme weather more than meteorology (Stilgoe 2015); and for climate impacts, vulnerability matters as much or more than the physical climate outcomes. In climate impacts assessment, vulnerability and exposure are considered separately to physical outcomes, but for climate geoengineering such a systematic approach is currently lacking. At best simplistic indicators are used for weighting impacts, and often issues of vulnerability are simply passed over, with perhaps a brief caveat (see Table 1).

Varied vulnerability to factors such as heatwaves, drought, or the timing of rainfall or frosts could exacerbate distributional inequalities. The simplistic indicators used in modelling, such as economic value, crop production or demographic weighting, do not reflect the reality that "in different regions different kinds of changes matter ... [and] relevant physical indicators for an assessment of SRM impacts are likely to vary between and even within regions" (Heyen et al 2015: 12). Most modelling 
also presupposes that all affected populations have the same underlying preferences. But: "even limited variation in actors' preferences about a target climate state can significantly change assessments of regional disparities from SRM" (Heyen et al 2015: 2). Once additional climate variables - beyond average temperature and precipitation - are considered, the likelihood of such disagreements grows. As a result, those who control the choice of model, the choice of criteria and the weightings given to different factors hold a great deal of discursive power.

Moreno-Cruz et al (2012) contrast SRM deployment under outcomes weighted by 'utilitarian' economic output, and 'egalitarian' population numbers. They estimate that: "precipitation induced population-weighted damages will increase by $51 \%$ if we optimize for output-weighted temperature damages ... [but] minimizing population-weighted precipitation changes simultaneously compensates for [only] 69\% of utilitarian temperature damages" (p659). In other words, while there are significant overlaps, political contestation could well result from different underlying values. Aaheim et al (2015) model economic consequences, and also find a mix of winners and losers from SRM, with some regions where the economic effects are negative in all their scenarios.

Increasing computational capacity and improved data has tempted modellers to try to assess distributional implications in such ways, potentially generating useful inputs for political discussion. Nonetheless technical limitations of climate models and data availability mean researchers have "tended to assess regional disparities on spatial levels ... that do not match with any socially meaningful categories" (Heyen et al 2015:13). Irvine et al (2010) make their conclusions based on just five 'illustrative' regions (US mainland, Western Europe, Eastern China, Australia and Brazil). Such aggregation "averages out small scale spatial differences ... [producing] more positive assessments of SRM's distributional effects" (Heyen et al 2015:13). Modellers also aggregate temporally over multi-year periods, thus potentially underweighting changes in annual variability and extreme events.

Aggregation is just one of the ways in which uncertainty - which multiplies at smaller scales - is deemphasized. Moreover, vulnerability is not just a function of location, for example, being dramatically different for waged and subsistence populations in the same localities. Vulnerability is variegated in multiple dimensions. And some vulnerabilities would not be reduced significantly by SAI. SRM does not reduce ocean acidification, or its impacts on communities dependent on fisheries or the protective effects of growing reefs. Insofar as climate geoengineering exerts any deterrent on mitigation, such impacts would then be exacerbated. Such deterrent effects would also sustain existing injustices in the fossil energy system, particularly those associated with extraction of fossil fuels or the distributed effects of air pollution from combustion in power generation or vehicles.

\section{Revealed conceptions of justice}

Collectively - and perhaps in response to climate policy-makers' demands for greater certainty - this literature tends to treat models primarily as truth machines that can be refined and tweaked to provide an ever-improving representation or prediction of reality. It consistently proposes further research, rather than calling directly for deployment, although there is currently a live debate over the desirability of small scale field trials, which might help resolve some technical uncertainties (Dykema et al, 2014), but would not provide evidence of regional distributive effects (Lenferna et al, 2017). Despite a general cautiousness, several of the papers reviewed here encourage consideration 
of particular modulated forms of SAI deployment. Although modellers often question their approaches and assumptions, and take care to specify technical uncertainties, the mode of such questioning rarely engages with more fundamental questions regarding the purpose or nature of modelling, nor the values and conceptions of justice embedded in the practices of modelling. I would speculate that this may represent defensiveness about the validity of climate modelling resulting from political controversy and the attacks of climate denialists (as described by Brown 2010); but as shown in the preceding section, it can have serious implications. Here I briefly summarize the largely unquestioned conceptions of justice revealed in the modelling literature.

In modelling efforts to minimise trade-offs and 'optimise' SAI, the approach to ethics and justice is primarily consequentialist (embedded in a liberal social imaginary of risk-management (Groves 2014)). Harms and benefits experienced by people are central to modelling approaches and interpretation, rather than, for example, deontological rules of action. The literature tends to overlook the prospect that not all those disadvantaged by climate change could be compensated by $\mathrm{SAl}$, and indeed some may even experience a worse situation; or engages with it only in ways that treat these losers as acceptable collateral in a utilitarian balance. The underlying assumptions rarely offered explicitly - are broadly utilitarian: justice is found in minimising aggregate suffering, or maximising aggregate wellbeing (Sinnott-Armstrong 2015).

These underlying philosophies are sometimes accompanied by distributional conceptions of justice, which particularly reflect Rawlsian western liberal approaches (Rawls 1971; Lamont and Favor 2013). A few modellers (eg Moreno-Cruz et al 2012) pay attention to the regional distribution of climate outcomes, and explore ways to minimise harms to the most disadvantaged groups. While the Pareto-optimisation approaches typically applied are rather utilitarian, the idea that disparities are acceptable only where they benefit the worst off (Rawls' 'difference principle') also seems influential. However, as the preceding sections show, claims about the distributional justice of SAI arising from the modelling literature are rather less certain than might first appear. The potential for countervailing mitigation-deterrent effects, for greater uncertainties and for differently variegated vulnerabilities all make it difficult to draw meaningful conclusions in a liberal justice paradigm. Earlier work on the distribution of benefits and burdens from climate change (eg Anthoff et al 2009) reinforces this concern. They find that, even within a consequentialist paradigm, introducing equityweightings substantially raises estimates of the social costs of carbon emissions, and such estimates differ by two orders of magnitude depending on the region to which the equity weights are normalised. Moreover, estimates may be more than twice as high if national rather than (global) regional impacts are aggregated. Such variations arise not only from differential warming, but also from variations in income, growth rates, and vulnerabilities. Given such a mix, we cannot presume that reducing climate impacts alone through climate geoengineering will necessarily promote justice. Collectively these factors also suggest that SAI might be less just than it might appear on the face of the models, especially if considered against a broader set of dimensions of justice. The next section begins to elaborate such a broader, plural approach, highlighting the desirability of supplementing distribution with procedure, correction and recognition (in ways - particularly drawing on capabilities and care - that transcend the binary of utilitarian/consequentialist and deontological approaches). 


\section{Conceptions of justice and discourses of climate geoengineering}

Climate change and its causes impact on multiple dimensions of justice. Simply examining distributional effects does not give a complete picture. Not only will political responses to climate change and climate geoengineering depend on varied impacts and preferences for particular climate outcomes, they will equally depend on how various cultures interpret and conceive of justice. Here I therefore identify ways in which broader conceptions of justice, beyond distribution, might be relevant - considering each of the plural dimensions identified by environmental justice scholars (eg Schlosberg 2007) in turn, and discussing briefly how they are framed out in the modelling literature. I then connect these framing effects with predominant discourses in climate geoengineering science and politics. This is a disembodied analysis, in which the principles embodied in climate geoengineering modelling are derived from the literature. It does not seek to impute motivations or beliefs to the modellers, but rather to surface some important constraints and limitations of their work, within the co-produced cultural, economic and institutional context of climate science and policy, with the hope of stimulating more reflexive responses.

\section{Broadening conceptions of justice}

Procedural justice focuses on the involvement of people in decisions that affect them. Just as public engagement in the development and design of new technology is critical because technologies can reshape moral landscapes and help lock-in particular social practices (Cotton 2014; Stilgoe 2015), so is public engagement in the design of models. As Bohman (1999) argues, public engagement in research design can support a pragmatic politics of inclusion, turning expert knowledge into a shared resource and supporting emergent publics to overcome disadvantage. But with rare exceptions, models and scenarios are typically constructed with no consultation of publics, which could helpfully be used to inform the choices of technologies, parameters or scenarios to model or even to shape the criteria informing the research as a whole (Bellamy et al 2014). ${ }^{(6)}$ This shortcoming privileges expertise, fails to recognise the necessarily partial nature of scientific knowledge (Ottinger 2013) and treats justice as something determined by elite institutions, rather than something participatory and procedural (McLaren et al 2013). Such procedural aspects are especially important insofar as climate geoengineering converts future climates into chosen, intentional artifacts, rather than unintended side effects of other beneficial activities. Intentionality reconfigures moral considerations (Morrow 2014a). It also makes it as important to scrutinise the implications of not using the technologies as the implications of deployment, and introduces new dynamics and challenges to international politics. But the addition of fair procedure alone still leaves the analysis within the standard consequentialist paradigm of the dominant social imaginary.

We begin to escape this paradigm by understanding the ways in which effective procedural justice and participatory parity demand recognition of people's status as full moral equals in society (Fraser and Honneth 2003). In largely ignoring vulnerabilities, and aggregating across multiple individuals, the dominant paradigm (and the models that reflect it) rather presuppose an artificial equality. Real world capacities to participate are instead highly variegated, and often constrained by institutional and cultural misrecognition. Similarly in applying implicit value assumptions about universal and equal preferences and criteria, the models fail to recognise real cultural variation. Justice as recognition demands taking account of existing difference, not just of our common humanity. 
Lack of attention to variation in vulnerability also exposes the ways in which conceptions of justice drawing on capabilities (Sen 2009) or care (Held 2006) are overlooked in considering the implications of the models. The capabilities approach focuses on justice as freedom - enabled by universal enjoyment of essential capabilities for functioning such as political participation, health and education. Yet actually existing capabilities are unequal. Justice in capability terms demands investment in capabilities, building power, enabling people and communities to function without dependency and domination. Like the ethics of care, it implies a focusing of our capacity to care on those who are vulnerable, ideally supporting them to obtain functioning and autonomy.

Rather than supporting building capabilities and thus social resilience, the climate modelling approaches and practices instead effectively prioritize the 'removal of a hazard' (the physical climate outcome). This represents a hierarchical model of control that is at worst a form of domination and at best, elitist paternalism. It treats those affected by climate change as powerless victims, not as potentially capable actors able to participate in determining the conditions of their lives - including participating in climate politics. This territory is implicitly reserved for the scientific and political elites - notably in the countries which dominate climate geoengineering research: the US, UK, Germany and to a lesser degree, China. Moreover, if SRM merely masks the threat of climate injustice to future generations, rather than structurally or institutionally removing it in the way mitigation and adaptation do (Smith 2012), then there is an equivalent intergenerational injustice involved. Put another way, mitigation and adaptation would appear inherently more supportive of future people's freedoms and capabilities because they reduce vulnerability to domination, especially if the underlying interventions, in energy systems for example, are undertaken with attention to fair distribution, recognition and procedure (Jenkins et al 2016). But this distinction is not acknowledged (or perhaps cannot be acknowledged) in the ways the models construct affected populations.

Finally, in ignoring existing inequalities, vulnerabilities and misrecognition, the modelling literature tends to reinforce a 'clean sheet' framing that risks excluding corrective or reparative justice. Reconciliation, reparation and even punishment can be central to justice, especially where vulnerability is a product of previous injustice. So restrictions and financial burdens imposed on carbon-intensive corporations and nations by accelerated mitigation and adaptation financing can be understood as a concrete representation of climate justice. Corrective or restorative justice also ensures that a focus on the victims of climate change does not cause us to ignore the perpetrators: which seems critical as addressing the problem demands changes in the behaviours of wealthy consumers and investors, particularly with respect to energy. Space precludes a deeper exploration of restorative justice here, but it seems clear that whether the aim is 'punishment' of 'climate criminals', or reconciliation between the perpetrators and victims of climate change, climate geoengineering - as constructed in the modelling described above - acts to dismiss both the need for, and possible mechanisms of, such corrective justice. Moreover any moral hazard effect also reduces the corrective implications of mitigation and adaptation policy, leaving those who have profited from the causes of climate change to continue to enjoy their benefits. Ways in which such effects could be countered, enabling geoengineering to support restorative justice, merit further investigation, especially in a context in which they might be considered as forms of climate repair or restoration (McLaren 2018). 


\section{Framing out justice, ignoring power}

The foregoing suggests that the modelling literature embodies narrow, largely utilitarian, conceptions of justice. Space precludes a full elaboration of the implications of these presumptions, or a discussion of the extent to which these conceptions accurately reflect or apply particular theories of justice. Here I focus on one aspect, the lack of plurality demonstrated. I outline how a richer understanding of justice might instead reveal and begin to respond to the power relations embodied in the models and related narratives of climate change. Here power is understood as asymmetric capability or agency (Stirling 2014).

The technological optimism of the modelling literature frames SAI as practical, manageable and governable. The counterfactual of unabated climate change reproduces a 'political realism' in which mitigation remains minimal. Together these risk a form of post-political, technological solutionism (McLaren 2016b), which presents another source of moral hazard. In the face of the constraints and difficulties of international climate politics, it should not be surprising that researchers and modellers are keen to explore climate geoengineering, even while they continue to advocate accelerated mitigation and adaptation. However, the solutionist mind-set redefines problems such that the novel technology appears as the solution, notably in ways that bypass messy political, cultural or behavioural changes (Morozov 2013). Reducing consumption, changing profligate lifestyles, or adopting costly or inconvenient practices becomes not only impractical but also unnecessary in solutionist responses to climate change. Yet these are the responses typically advocated as essential to deliver climate justice (Athanasiou and Baer 2002), and similarly, consideration of demand-side responses is critical to energy justice (Jenkins et al 2016).

Solutionism shifts power and authority from politics to science and technology, but typically without democratising the latter. Simultaneously, the high apparent leverage of SAI forms of SRM could be expected to concentrate power, giving it an essentially centralising and autocratic 'social constitution' (Szersynski et al 2013). In this light, a scheme of SRM designed to benefit the poorest (such as those explored by Moreno-Cruz et al 2012) would seem unlikely to be implemented even if technically feasible (Stilgoe 2015). The new climates resulting from SAl suggest incentives for powerful nations to prefer distributional patterns that could impose greater risks on poorer and less powerful groups. Such an outcome need not rely on unilateral imposition, as poorer countries might well accede to a distributional schema designed by the powerful for its generic benefits or for other political reasons. Nor can we assume that the political interests of poor country governments would coincide with the interests of their poorest inhabitants.

Power is perhaps overlooked for the same reasons as moral hazard: SRM modellers typically treat technology as something morally neutral, on which they can act, but which does not act on them. But technologies not only cause us to adjust our behaviours but also condition our agency and reframe our moral and political choices (Verbeek 2011; Cotton 2014). Even the technical capacity to model climate geoengineering has such a reframing effect, in that simulations based on SRM open questions of desirable climate outcomes or 'designer climates' (Wiertz 2016). Justice is only one dimension of the moral choices raised here, but other aspects lie beyond the scope of this paper.

If the technologies of climate modelling - like those of climate geoengineering - are understood as embedded co-constituted parts of socio-technical systems, it becomes easier to understand how modelling designs exert agency within a system; how moral questions extend to the design and 
assumptions of models, not only their use and interpretation; and that values and facts cannot be treated as independent, but are different aspects of a system in which politics, power and technology are co-constituted. Of course justice should be similarly conceptualised - as it is in environmental justice theory - as something negotiated, contested and co-constituted, not as something separate, abstract and ideal. By treating models as games of make-believe, researchers could not only open up climate geoengineering appraisal (Bellamy 2016) but also create opportunities to experiment (both with, and on) the models, as Stilgoe suggests (2015), in ways that assist with deliberation and negotiation over both climate technologies and climate justice. There is great potential for scientific collaborations across disciplines to conduct different analyses with the models, and conduct modelling experiments using different concepts of justice to help challenge the shortcomings identified here. Social science is not only valuable for communicating the results of modelling to the public and policy makers, but integrated into research programs it can help introduce social values and concerns into the design of modelling experiments.

Of course, models are only part of the complex machinery used to anticipate the future. We cannot expect modelling and modellers to solve all these problems alone. But in the case of climate policy, modelling is central not only to other forms of anticipation and speculation (Stilgoe 2015) but to the politics and epistemology of climate change. So it is critical - for climate and energy research - to challenge how models are constructed and deployed, and to understand how political and social values - for example about risk, participation or justice - are embodied through design assumptions. Re-building models to respond to such an understanding will not be easy. Researchers should seek to recognize and understand the limitations of models, and seek to compensate for them. That the models will nevertheless remain incomplete does not render them irrelevant or inappropriate. It does, however, mandate that the models be put into dialogue with ethical and moral discourse. Designing models and experiments on models that deploy a reflexive approach to SAl, as in some ways a subject rather than only an object, should be the goal. Modelling should experiment with a wider range of counterfactuals; with scenarios designed through public engagement; with more random variation to simulate control problems; and more experiments using real human beings as control actors, representing diverse interests. This means designing trans-disciplinary research programs that genuinely engage with political, social and cultural dimensions of climate policy, not merely seeking to abstractly model the political and social alongside the scientific. Such approaches would appear urgently needed in a policy world which appears increasingly polarized over the desirability of SRM research and testing in the light of the $1.5^{\circ} \mathrm{C}$ climate aspiration agreed in Paris (Nicholson et al 2017). Otherwise we might fear a repetition of the process in which carbon geoengineering has been absorbed into climate pathways models without proper assessment of its technical limitations or ethical risks (Anderson 2015; Peters and Geden 2017).

\section{Conclusions}

In summary, the values and conceptions of justice revealed as underpinning SRM modelling exercises and the representations they produce are predominantly consequential rather than procedural; attending to the distribution of benefits and harms, rather than to underlying capabilities; individualist and aggregative rather than collective; fail to raise questions of recognition, vulnerability and reparation; and largely rooted in western, liberal conceptions of justice which 
ignore international cultural and political variations. The literature mainly displays a utilitarian bent, accepting and reinforcing substantial economic inequality, in the name of political realism presuming that radical socio-economic change is infeasible, even while exploring ways to reduce other dimensions of climate injustice. This does not necessarily reflect the personal convictions of the researchers involved, but is a product of practical limitations of modelling, combined with the co-produced discourses, imaginaries and institutions that constrain and condition the agency of modellers.

Although SAI might offer justice gains when contrasted with unabated climate change, when compared with perfect mitigation it appears much less just. But neither unabated climate change nor perfect mitigation is plausible: it is essential to explore relative justice effects in responses involving mixtures of more or less mitigation, adaptation and climate geoengineering. In this context it is problematic that SAI techniques would not only generate different winners and losers with reconfigured climates but also distribute power, freedoms and capabilities in new and potentially harmful ways across populations and generations.

The climate geoengineering modelling literature also tends to overlook or devalue issues such as the relative vulnerability of affected populations; extant obligations resulting from disproportionate historical contributions to emissions; the distribution of power to decide over the design of any SAI intervention; the extent to which uncertainties in controllability and governance of SAI could undermine efforts to mitigate distributional impacts; the ethical implications of the intentional creation of new climates. All these would appear to contribute to the risks of a 'moral hazard' effect delaying or deterring mitigation (McLaren 2016a), and thus increasing exposure to any harms from climate geoengineering, residual climate change and sustained extraction and use of fossil fuels in energy systems.

In part these are products of a broader epistemic problem of implicitly yet hubristically treating and portraying climate and energy models as truth-machines rather than games of make-believe or sandpits. This paper has suggested particular shortcomings in the climate geoengineering literature's often implicit assumptions of effectiveness, precision and controllability, its metrics and methods of aggregation, and its use of an excessive counterfactual of unabated climate change. The first means that risks of failure, moral hazard and uncertain distributional effects over space and time all receive inadequate attention. The second fails to recognise localised and variegated vulnerability and existing inequalities that might be exacerbated. And the last misrepresents the avoidance of a high greenhouse gas world as impractical and politically unrealistic, focusing attention on technological means of avoiding the extremes of climate impacts and away from moral obligations arising from historic emissions and other injustices of energy systems.

As a result, the dominant constructions of justice in climate geoengineering appear likely to bolster the existing power of global, Northern elites to resist demands for climate justice from predominantly Southern subaltern groups. In failing to engage with the heterogeneity of justice as procedure, reparation, freedom, recognition, or care for the vulnerable the discipline risks diminishing the prospects of responses to climate change that genuinely enhance global justice. And, under pressure to provide pathways to a $1.5^{\circ} \mathrm{C}$ world, there seems a real risk that the promise of SRM will be adopted as yet another techno-fix for neo-liberal climate policy. 
The promise of climate geoengineering - control over the climate - is also a threat, if future climates might be controlled or chosen by the powerful, in line with their interests and values. The modelling outcomes indicate that it would be unfair if 'interests' referred only to climate preferences. It would be even worse if the possibility of climate geoengineering were mobilised to restrict mitigation and protect elite financial interests in the current high-carbon fossil-fuelled energy system and economy. The question of who controls the technology is clearly critical. But even while the technologies themselves remain imaginaries, modelling also raises the question of who controls the discourses that effectively arbitrate what is and is not practical and just in climate policy. Focusing on the outcomes of models avoids accountability for the assumptions and conceptions of justice involved in building them. Rather than promoting deliberation and reflection, the scientific discourses risk prematurely closing down debate. Just like the moral implications of climate geoengineering, the moral implications of modelling must be taken seriously in design as well as use.

\section{Acknowledgements}

This research did not receive any specific grant from funding agencies in the public, commercial, or not-forprofit sectors. This paper began as a presentation at the Plurality and Politics of Environmental Justice seminar at UEA in June 2015. I want to thank the organisers and participants for the inspiring and constructive discussion. It was substantially rewritten during a short residency at the Institute for Advanced Sustainability Studies (IASS) in Potsdam in June 2016. Stefan Schäfer and Mark Lawrence for the opportunity, and to seminar discussants at IASS for their detailed feedback. My thanks are also due to several anonymous reviewers, whose comments helped me improved the paper significantly. Gordon Walker, Nils Markusson, Thilo Wiertz and Elizabeth Cooper also read and commented on various drafts: they all deserve my gratitude too. Errors of course remain entirely my responsibility.

\section{References}

Aaheim, A., Romstad, B., Wei, T, Kristjánsson, J.E., Muri, H., Niemeier, U. and Schmidt, H. 2015. An economic evaluation of solar radiation management. Science of the Total Environment, 532: 61-69

Anderson, K. 2015. Duality in Climate Science. Nature Geoscience 8 (Dec) 898-900.

Anthoff, D., C. Hepburn and R.S.J. Tol, 2009. Equity weighting and the marginal damage costs of climate change. Ecological Economics, 68(3): 836-849, doi: 10.1016/j.ecolecon.2008.06.017

Armstrong, C. 2017. 'Climate Change'. Oxford Research Encyclopedia of Politics. DOI: 10.1093/acrefore/9780190228637.013.231

Athanasiou, T. and Baer, P. 2002. Dead Heat: global justice and global warming. New York: Seven Stories Press.

Baatz, C. 2016. Can We Have It Both Ways? On Potential Trade-Offs Between Mitigation and Solar Radiation Management. Environmental Values 25: 29-49.

Bala, G, Duffy, P.B. and Taylor K.E. 2008. Impact of geoengineering schemes on the global hydrological cycle. PNAS, 105(22):7664-69 doi:10.1073pnas.0711648105

Ban-Weiss G.A. and Caldeira, K. 2010. Geoengineering as an optimization problem. Environ. Res. Lett. 5(034009):9pp doi:10.1088/1748-9326/5/3/034009 
Bellamy, R., J. Chilvers, and N.E. Vaughan, 2014. Deliberative Mapping of options for tackling climate change: Citizens and specialists 'open up' appraisal of geoengineering. Public Understanding of Science, 25(3): 269-286

Bellamy, R. 2016. A sociotechnical framework for governing climate engineering. Science, Technology, \& Human Values 41(2):135-62.

Bickerstaff, K. Walker, G. and Bulkeley, H. 2013. "Introduction: Making sense of Energy Justice." In Energy Justice in a Changing Climate, 1-13. London: Zed Books.

Bohman, J. 1999. Democracy as Inquiry, Inquiry as Democratic: Pragmatism, Social Science, and the Cognitive Division of Labor. American Journal of Political Science 43(2): 590-607. doi:10.2307/2991808

Brown, A.S. 2010. Climate models and their critics. The Bent Of Tau Beta Pi (Winter): 19-24, online at https://www.tbp.org/pubs/features/w10brown.pdf

Cairns, R. and A. Stirling, 2014. 'Maintaining planetary systems' or 'concentrating global power?' High stakes in contending framings of climate geoengineering. Global Environmental Change, 28: 25-38

Cao, L., L. Duan, G. Bala, K. Caldeira, 2017. Simultaneous stabilization of global temperature and precipitation through cocktail geoengineering. Geophys. Res. Lett. 37 (D6). doi: 10.1002/2017GL074281.

Corner, A. and Pidgeon, N. 2014. Geoengineering, climate change scepticism and the 'moral hazard' argument: an experimental study of UK public perceptions. Phil. Trans. R.Soc. A 372. doi:10.1098/rsta.2014.0063

Corry, O. 2015. Review of 'Models as Make-Believe' by Adam Toon. British Journal of Aesthetics 55(1):126-28.

Cotton, M. 2014. Ethics and Technology Assessment: A Participatory Approach. Berlin: Springer-Verlag.

Curry, C.L., Sillmann, J., Bronaugh, D. Alterskjaer, K and 10 others. 2014. A multimodel examination of climate extremes in an idealized geoengineering experiment, J. Geophys. Res. Atmos., 119:3900-23.

doi:10.1002/2013JD020648

Curry J.A. and, P.J. Webster, 2011. Climate science and the uncertainty monster. Bull Am Meteorol Soc. 92:1667-1682.

Driscoll, S., Bozzo, A., Gray, L.J., Robock, A and Stenchikov, G. 2012. Coupled Model Intercomparison Project 5 (CMIP5) simulations of climate following volcanic eruptions, J. Geophys. Res. 11(D17105).

doi:10.1029/2012JD017607

Dykema, J. D. Keith, J.G. Anderson, and D. Weisenstein, 2014. Stratospheric controlled perturbation experiment (SCoPEx): a small-scale experiment to improve understanding of the risks of solar geoengineering. Philosophical Transactions of the Royal Society A, 372, doi: 10.1098/rsta.2014.0059

Edwards, P.N. 2011. History of climate modeling. WIREs Clim. Change 2:128-39. doi: 10.1002/wcc.95

Ferraro, A.J., A.J. Charlton-Perez, E.J. Highwood, 2014. A Risk-Based Framework for Assessing the Effectiveness of Stratospheric Aerosol Geoengineering. PLOS ONE 9(2): e88849. doi:10.1371/journal.pone.0088849

Flato, G.M. 2011. Earth system models: an overview. WIREs Clim. Change, 2:783-800. doi: 10.1002/wcc.148

Fraser, N. and Honneth, A. 2003. Redistribution or recognition? A political-philosophical exchange. London: Verso.

Fuss, S., J.G. Canadell, G.P. Peters, M. Tavoni, R.M. et al, 2014. Betting on negative emissions. Nature Climate Change 4: 850-53.

Galarraga, M. and Szerszynski, B. 2012. "Making climates: solar radiation management and the ethics of fabrication." In Engineering the Climate: The Ethics of Solar Radiation Management, edited by C.J. Preston, 221-35. Lanham, MD: Rowman and Littlefield. 
Gardiner, S.M. 2010. "Is 'Arming the Future' with Geoengineering Really the Lesser Evil?” In Climate Ethics: Essential readings, edited by S.M. Gardiner, S. Caney, D. Jamieson and H. Shue, 284-312. Oxford: Oxford University Press.

Groves, C. Care, Uncertainty and Intergenerational Ethics. London: Palgrave Macmillan, 2014.

Hansson, A. 2014. Ambivalence in calculating the future: the case of re-engineering the world. Journal of Integrative Environmental Sciences, 11(2): 125-142, DOI:10.1080/1943815X.2014.921629

Haywood, J.M., Jones, A., Bellouin, N and Stephenson, D. 2013. Asymmetric forcing from stratospheric aerosols impacts Sahelian rainfall. Nature Climate Change, 3:660-65. doi:10.1038/NCLIMATE1857

Held, V. 2006. The Ethics of Care: Personal, Political, Global. Oxford: Oxford University Press.

Heyen D., Wiertz, T. and Irvine, P. 2015. 'Radiation Management Impacts: Limitations to Simple Assessments and the Role of Diverging Preferences.' IASS Working Paper. Potsdam: Institute for Advanced Sustainability Studies, doi.org/10.2312/iass.2015.001

Horton, J. and D. Keith, 'Solar geoengineering and obligations to the global poor.' pp79-92 in C.J. Preston (ed) Climate Justice and Geoengineering: Ethics and Policy in the Atmospheric Anthropocene. London: Rowman and Littlefield, 2016.

Hourdequin, M. 'Justice, recognition and climate change.' pp33-48 in C.J. Preston (ed) Climate Justice and Geoengineering: Ethics and Policy in the Atmospheric Anthropocene. London: Rowman and Littlefield, 2016.

Irvine, P.J., Ridgwell, A. and Lunt, D.J.s Geophysical Research Letters, 37(L18702):6pp. doi:10.1029/2010GL044447

Irvine, P.J., Sriver, R.L. and Keller, K. 2012. Tension between reducing sea-level rise and global warming through solar-radiation management. Nature Climate Change, 2:97-100. doi: 10.1038/NCLIMATE1351

Jackson, L.S., Crook, J.A., Jarvis, A. Leedal, D., Ridgwell, A., Vaughan, N. and Forster, P.M. 2015. Assessing the controllability of Arctic sea ice extent by sulfate aerosol geoengineering. Geophysical Research Letters 42:122331. doi:10.1002/2014GL062240

Jasanoff, S. 2003. Technologies of humility: citizen participation in governing science. Minerva 41:223-44

Jenkins, K., D. McCauley, R. Heffron, H. Stephan and R. Rehner, 2016. Energy justice: A conceptual review Energy Research \& Social Science 11 (2016) 174-182, DOI: 10.1016/j.erss.2015.10.004

Jones, A.C., J.M. Haywood, N. Dunstone, K. Emanuel, M.K. Hawcroft, K.I. Hodges \& A. Jones, 2017. Impacts of hemispheric solar geoengineering on tropical cyclone frequency. Nature Communications, 8: 1382, DOI: 10.1038/s41467-017-01606-0

Keith, D. 2013. A Case for Climate Engineering. Cambridge MA: MIT Press/Boston Review Books.

Kintish, E. 2010. Hack the Planet. London: Wiley.

Koplewitz, G. 2015. Engineering The Climate. Harvard Political Review, August $28^{\text {th }}$. Available online at http://harvardpolitics.com/world/engineering-climate/

Kravitz, B., MacMartin, D.G., Robock, A., Rasch, P.J. and 14 others. 2014. A multi-model assessment of regional climate disparities caused by solar geoengineering. Environ. Res. Lett. 9(074013):7pp. doi:10.1088/17489326/9/7/074013

Lahsen, M. 2005. Seductive Simulations? Uncertainty Distribution Around Climate Models. Social Studies of Science 35:895. doi:10.1177/0306312705053049

Lamont, J. and C. Favor, 2013. Distributive Justice. Stanford Encylopedia of Philosophy. Available at: http://plato.stanford.edu/entries/justice-distributive/ 
Lenferna, G.A., Russotto, R.D., Tan, A., Gardiner, S.M. and Ackerman, T.P. 2017. Relevant climate response tests for stratospheric aerosol injection: A combined ethical and scientific analysis. Earth's Future, 5: 577-591. doi:10.1002/2016EF000504

Linnér, B.-O. and V. Wibeck, 2015. Dual high-stake emerging technologies: a review of the climate engineering research literature. WIREs Clim Change, 6: 255-268. doi:10.1002/wcc.333

Lunt, D.J., Ridgwell, A., Valdes, P.J. and Seale, A. 2008. "Sunshade World": A fully coupled GCM evaluation of the climatic impacts of geoengineering. Geophysical Research Letters 35(L12710):5pp.

doi:10.1029/2008GL033674

MacMartin, D.G., Keith, D.W., Kravitz, B. and Caldeira, K. 2013. Management of trade-offs in geoengineering through optimal choice of non-uniform radiative forcing. Nature Climate Change, 3:365-68.

doi:10.1038/NCLIMATE1722

MacMartin, D.G., Kravitz, B., Keith, D.W. and Jarvis. A. 2013. Dynamics of the coupled human-climate system resulting from closed-loop control of solar geoengineering. Climate Dynamics 43(1/2):243-58.

MacMartin D.G., Caldeira K. and Keith D.W. 2014. Solar geoengineering to limit the rate of temperature change. Phil. Trans. R. Soc. A 372. doi:10.1098/rsta.2014.0134

MacMartin, D.G., B. Kravitz and P.J. Rasch, 2015. On solar geoengineering and climate uncertainty. Geophysical Research Letters, 42(17) 7156-7161 DOI: 10.1002/2015GL065391

Mamo, L. and Fishman, J.R. 2013. Why Justice? Introduction to the Special Issue on Entanglements of Science, Ethics, and Justice. Science, Technology, \& Human Values 38(2):159-75.

Markusson, N., M.D. Gjefsen, J.C. Stephens and D. Tyfield, 2017. 'The political economy of technical fixes: The (mis)alignment of clean fossil and political regimes'. Energy Research \& Social Science 23: 1-10.

McCusker, K.E., Battisti, D.S. and Bitz, C.M. 2015. Inability of stratospheric sulfate aerosol injections to preserve the West Antarctic Ice Sheet, Geophys. Res. Lett., 42:9pp doi:10.1002/2015GL064314.

McLaren, D.P., Krieger, K. and Bickerstaff, K. 2013. "Justice in energy system transitions: the case of carbon capture and storage." In Energy Justice in a Changing Climate, edited by K. Bickerstaff, G. Walker and $\mathrm{H}$. Bulkeley, 158-81. London: Zed Books.

McLaren, D.P. 2016a. Mitigation deterrence and the "moral hazard" of solar radiation management. Earth's Future, 4: 596-602. doi:10.1002/2016EF000445

McLaren, D.P. 2016b. 'Framing out justice: the post-politics of climate engineering discourses.' In Climate Justice and Geoengineering: Ethics and Policy in the Atmospheric Anthropocene, edited by C.J. Preston. London: Rowman and Littlefield.

McLaren, D.P. 2017. Mirror, mirror. Fairness and justice in climate geoengineering. PhD thesis. Lancaster University. doi: 10.17635/lancaster/thesis/184

McLaren, D.P. 2018. In a broken world: Towards an ethics of repair in the Anthropocene. The Anthropocene Review, Online ahead of print: April 12, 2018 https://doi.org/10.1177/2053019618767211

Moreno-Cruz, J.B., Ricke, K.L. and Keith, D.W. 2012. A simple model to account for regional inequalities in the effectiveness of solar radiation management. Climatic Change 110:649-68. doi:10.1007/s10584-011-0103-z

Morozov, E. 2013. To save everything click here. Penguin, London.

Morrow, D. 2014a. Starting a flood to stop a fire? Some moral constraints on solar radiation management. Ethics, Policy \& Environment, 17(2):123-38, doi:10.1080/21550085.2014.926056

Morrow D.R. 2014b. Ethical aspects of the mitigation obstruction argument against climate engineering research. Phil. Trans. R.Soc. A 372:20140062. http://dx.doi.org/10.1098/rsta.2014.0062 
Ottinger, G. 2013. Changing Knowledge, Local Knowledge, and Knowledge Gaps: STS Insights into Procedural Justice. Science, Technology, \& Human Values 38(2) 250-270.

Nicholson, S., S. Jinnah \& A. Gillespie, 2017. Solar radiation management: a proposal for immediate polycentric governance. Climate Politics. Published online: 04 Dec 2017. doi: 10.1080/14693062.2017.1400944

Niemeier, U., H. Schmidt, K. Alterskjær and J.E. Kristjánsson, 2013. Solar irradiance reduction via climate engineering: Impact of different techniques on the energy balance and the hydrological cycle. Journal of Geophysical Research: Atmospheres, 118: 11,905-11,917, doi:10.1002/2013JD020445

Peters, G.P. and Geden, O., 2017. Catalysing a political shift from low to negative carbon, Nature Climate Change, 7: 619-62 doi:10.1038/nclimate3369

Rawls, J. 1971. A Theory of Justice. Cambridge MA: Belknap.

Ricke, K.L., Morgan, M.G. and Allen, M.R. 2010. Regional climate response to solar-radiation management. Nature Geoscience, 3:537-541 DOI: 10.1038/NGEO915

Robock, A., Oman, L. and Stenchikov, G.L. 2008. Regional climate responses to geoengineering with tropical and Arctic SO2 injections, J. Geophys. Res., 113(D16101):15pp doi:10.1029/2008JD010050

Royal Society, 2009. Geoengineering the climate: science, governance and uncertainty. London: Royal Society. Schlosberg, D. 2007. Defining Environmental Justice: Theories, Movements, and Nature. Oxford: Oxford University Press.

Schlosberg, D. 2012. Climate Justice and Capabilities: A Framework for Adaptation Policy. Ethics and International Affairs, 26(04):445-61. doi:10.1017/S0892679412000615

Schmidt, H., K. Alterskjær, D. Bou Karam, O. Boucher, A. Jones, J. E. Kristjansson, U. Niemeier, M. Schulz, A. Aaheim, F. Benduhn, M. Lawrence and C. Timmreck, 2012. Solar irradiance reduction to counteract radiative forcing from a quadrupling of $\mathrm{CO}_{2}$ : climate responses simulated by four earth system models. Earth Syst. Dynam., 3: 63-78.

Sen, A. 2009. The Idea of Justice. London: Allen Lane.

Shackley, S. and Wynne, B. 1996. Representing Uncertainty in Global Climate Change Science and Policy: Boundary-Ordering Devices and Authority. Science, Technology, \& Human Values, 21(3): 275-302.

Shrader-Frechette, K. 2002. Environmental Justice: creating equality, reclaiming democracy. Oxford: Oxford University Press.

Shue, H. 2014. Climate justice: Vulnerability and Protection. Oxford: Oxford University Press.

Sinnott-Armstrong, W. 2015. Consequentialism, Stanford Encyclopedia of Philosophy (Winter 2015 Edition), Edward N. Zalta (ed.), Available at: http://plato.stanford.edu/archives/win2015/entries/consequentialism/

Smith, P.T. 2012. "Domination and the ethics of solar radiation management." In Engineering the Climate: The Ethics of Solar Radiation Management, edited by C.J. Preston, 43-61. Lanham, MD: Rowman and Littlefield.

Sovacool, B.K., S.E. Ryan, P.C. Stern, K. Janda, G. Rochlin, D. Spreng, M.J. Pasqualetti, H. Wilhite and L. Lutzenhiser, 2015. Integrating social science in energy research. Energy Research \& Social Science, 6:95-99, DOI: $10.1016 /$ j.erss.2014.12.005

Stilgoe, J. 2015. Experiment Earth: Responsible Innovation in Geoengineering. London: Routledge.

Stirling, A. 2003. "Risk, uncertainty and precaution: Some instrumental implications from the social sciences." In Negotiating change, edited by F. Berkhout, M. Leach, and I. Scoones, 33-76. London: Elgar.

Stirling, A. 2014. 'Transforming power: Social science and the politics of energy choices', Energy Research \& Social Science 1:83-95. 
Sundberg, M. 2007. Parameterizations as Boundary Objects on the Climate Arena. Social Studies of Science $37(3): 473-88$.

Sundberg, M. 2011. The Dynamics of Coordinated Comparisons: How Simulationists in Astrophysics, Oceanography and Meteorology Create Standards for Results. Social Studies of Science 41(1):107-25.

Svoboda, T. 2016. Aerosol geoengineering deployment and fairness. Environmental Values 25:51-68.

Swyngedouw, E. 2010. 'Apocalypse Forever? Post-political Populism and the Spectre of Climate Change.' Theory, Culture \& Society, 27 (2-3): 213-32.

Szerszynski, B., Kearnes, M., Macnaghten, P., Owen R. and Stilgoe, J. 2013. Why solar radiation management geoengineering and democracy won't mix. Environment and Planning A 45:2809-16.

Tilmes, S., et al. 2013. The hydrological impact of geoengineering in the Geoengineering Model Intercomparison Project (GeoMIP), J. Geophys. Res. Atmos., 118, 11,036-11,058, doi:10.1002/jgrd.50868.

Tilmes, S., A. Jahn, J. E. Kay, M. Holland, and J.-F. Lamarque, 2014. Can regional climate engineering save the summer Arctic sea ice? Geophys. Res. Lett., 41, 880-885, doi:10.1002/2013GL058731.

Toon, A. 2010. "Models as make-believe." In Beyond Mimesis and Convention edited by R. Frigg and M. Hunter, 71-96. Dordrecht: Springer.

Verbeek, P-P. 2011. Moralizing Technology: Understanding And Designing The Morality Of Things. Chicago IL: University of Chicago Press.

Wibeck, V. A. Hansson and J. Anselm, 2015. Questioning the technological fix to climate change - Lay sensemaking of geoengineering in Sweden. Energy Research \& Social Science 7: 23-30.

Wiertz, T. 2016. Visions of Climate Control: Solar Radiation Management in Climate Simulations. Science, Technology, \& Human Values 41(3):438-60. doi:10.1177/0162243915606524

Yu, X., J.C. Moore, X. Cui, A. Rinke, D. Ji, B. Kravitz, JH Yoon, 2015. Impacts, effectiveness and regional inequalities of the GeoMIP G1 to G4 solar radiation management scenarios. Global and Planetary Change 129: 10-22. 


\section{Endnotes}

1. Relevant events include the Climate Engineering Conferences and Symposium held in Berlin in 2014, 2015 and 2017; and Climate Engineering Summer Schools in Oxford (2013), Harvard (2014) and Heidelberg (2015).

2. Neither, however, could accelerated mitigation be expected to halt sea-level rise.

3. See for example: http://a-m-e-g.blogspot.se/2012/05/message-from-arctic-methane-emergency.html.

4. Cao et al (2017) even explore a 'cocktail' of SAl plus another proposed technique, cirrus cloud thinning. They suggest this could improve the global trade-off between precipitation and temperature effects, but not the regionally distributed impacts.

5. Strictly, given complexity, no future climate would be the same as a past climate. Yet the modelling literature often refers to 'restoring' climate states.

6. The Integrated Assessment of Geoengineering Proposals project (http://www.iagp.ac.uk) was an exception in that deliberative public engagement influenced both the research programme, and the scenarios modeled. 
Annex: Table 1: Key SRM/SAI modelling literature on regional impacts and disparities (to 2015)

\begin{tabular}{|c|c|c|c|c|}
\hline Paper & Robock et al 2008 & Irvine et al 2010 & Ricke et al 2010 & Schmidt et al 2012 \\
\hline $\begin{array}{r}\text { Model(s), scope, scale, } \\
\text { approach }\end{array}$ & $\begin{array}{l}\text { GISS Model E GCM, } \\
\text { continental/monsoon } \\
\text { region scale, } 5 \\
\text { simulations including } \\
\text { tropical and polar } \\
\text { focused SAI. Aerosol } \\
\text { modelling. }\end{array}$ & $\begin{array}{l}\text { HadCM3L GCM, } 16 \text { FUND } \\
\text { model world regions, } 12 \\
\text { simulations } \\
\text { (incrementally increasing } \\
\text { the \% of forcing } \\
\text { countered by SAI - } \\
\text { simulated by varying solar } \\
\text { irradiance). Plus weighted } \\
\text { analysis by crop } \\
\text { yield/population density. }\end{array}$ & $\begin{array}{l}\text { HadCM3L, } 54 \text { scenario } \\
\text { ensemble, } 23 \text { 'macro- } \\
\text { regions'. Comparing } \\
\text { regional normalised } \\
\text { temperature and } \\
\text { precipitation over time. } \\
\text { Uniformly distributed } \\
\text { aerosol modelling. }\end{array}$ & $\begin{array}{l}\text { Compare } 4 \text { Earth System } \\
\text { Model responses to a } \\
\text { standardised SRM } \\
\text { scenario (compensating } \\
\text { abrupt } 4 \times C O 2 \text { ) using } \\
\text { single simulations } \\
\text { (varying solar irradiance) } \\
\text { and multi-model } \\
\text { averages. Continental / } \\
\text { monsoon system scale. }\end{array}$ \\
\hline $\begin{array}{r}\text { Key finding(s) / } \\
\text { conclusion }\end{array}$ & $\begin{array}{l}\text { "consequences for } \\
\text { the African and Asian } \\
\text { summer monsoons } \\
\text { could be serious, } \\
\text { threatening the food } \\
\text { and water supplies to } \\
\text { billions of people" } \\
\text { (p.1) }\end{array}$ & $\begin{array}{l}\text { "it might be possible to } \\
\text { identify a level of SRM } \\
\text { geoengineering sufficient } \\
\text { to maintain the } \\
\text { Greenland ice sheet and } \\
\text { cool the climate } \\
\text { significantly ... without a } \\
\text { large reduction in global } \\
\text { precipitation } \\
\text { and exposing only a small } \\
\text { fraction of the Earth to } \\
\text { novel climates [outside } \\
\text { preindustrial to } 4 \times C O 2 \\
\text { bounds]" (p.1) }\end{array}$ & $\begin{array}{l}\text { "simulated temperature } \\
\text { and precipitation in large } \\
\text { regions ... diverge from } \\
\text { historical baselines in } \\
\text { different directions. ... it } \\
\text { may not be possible to } \\
\text { stabilize the climate in all } \\
\text { regions simultaneously" } \\
\text { (p.537). SAl brings all } \\
\text { regions closer to 1990s } \\
\text { conditions than under } \\
\text { unmitigated climate } \\
\text { change, but divergences } \\
\text { grow over time. }\end{array}$ & $\begin{array}{l}\text { For full warming } \\
\text { compensation of } 4 \times \mathrm{CO}_{2} \text {, } \\
\text { polar temperatures are } \\
\text { higher and tropical } \\
\text { temperatures lower } \\
\text { than pre-existing levels. } \\
\text { Regional precipitation } \\
\text { responses are highly } \\
\text { divergent, and may even } \\
\text { exceed changes under } \\
\text { unmitigated climate } \\
\text { change. }\end{array}$ \\
\hline Choice of counterfactuals & $\begin{array}{l}\text { IPCC SRES A1B BAU } \\
\left(2 \times \mathrm{CO}_{2} \text { by } 2030\right)\end{array}$ & $4 \times \mathrm{CO}_{2}$ climate & $\begin{array}{l}\text { IPCC SRES A1B BAU } \\
\left(2 \times \mathrm{CO}_{2} \text { by } 2030\right)\end{array}$ & $4 \times \mathrm{CO}_{2}$ climate \\
\hline $\begin{array}{r}\text { Approach to } \\
\text { uncertainties, } \\
\text { controllability \& } \\
\text { vulnerability }\end{array}$ & $\begin{array}{l}\text { Broad concern over } \\
\text { vulnerability to } \\
\text { monsoon changes. } \\
\text { Some scepticism } \\
\text { regarding } \\
\text { controllability (mainly } \\
\text { political). Little } \\
\text { discussion of } \\
\text { uncertainties. }\end{array}$ & $\begin{array}{l}\text { Vulnerability largely } \\
\text { reduced to crop yields } \\
\text { and population density. } \\
\text { Caveats regarding use of } \\
\text { single, low resolution } \\
\text { model, lack of cost- } \\
\text { benefit analysis. Results } \\
\text { described as illustrative }\end{array}$ & $\begin{array}{l}\text { Sub-regional interests } \\
\text { acknowledged. Very } \\
\text { limited discussion of } \\
\text { uncertainties and } \\
\text { controllability. }\end{array}$ & $\begin{array}{l}\text { Note that only limited } \\
\text { climate factors were } \\
\text { considered. Suggest } \\
\text { impact studies to assess } \\
\text { harms and benefits to } \\
\text { actual populations. Note } \\
\text { that the technology } \\
\text { implied is 'hypothetical' } \\
\text { but do not discuss } \\
\text { controllability. }\end{array}$ \\
\hline Citations (as of Dec 2017) & 204 & 34 & 103 & 72 \\
\hline $\begin{array}{r}\text { SRM preferable to } \\
\text { unmitigated climate change }\end{array}$ & no & Yes & Yes & Yes \\
\hline $\begin{array}{r}\text { SAI 'corrects' temperature } \\
\text { better than precipitation }\end{array}$ & yes & Yes & Yes & Yes \\
\hline $\begin{array}{r}\text { SRM has uneven } \\
\text { latitudinal effects }\end{array}$ & yes & Yes & - & Yes \\
\hline $\begin{array}{l}\text { Limited SRM preferable to } \\
\text { full temp compensation }\end{array}$ & - & Yes & Yes & Yes \\
\hline $\begin{array}{r}\text { Regional modulation } \\
\text { appears desirable }\end{array}$ & - & $?$ & - & - \\
\hline $\begin{array}{r}\text { Hemispheric SRM is } \\
\text { problematic }\end{array}$ & - & - & - & - \\
\hline $\begin{array}{r}\text { Considered weather } \\
\text { extremes }\end{array}$ & no & No & No & no \\
\hline $\begin{array}{r}\text { Aerosol SAI less effective } \\
\text { than solar dimming }\end{array}$ & - & - & - & ? \\
\hline
\end{tabular}




\begin{tabular}{|c|c|c|c|c|}
\hline Paper & $\begin{array}{l}\text { Moreno Cruz et al } \\
2012\end{array}$ & Macmartin et al 2013 & Niemeier et al 2013 & Curry et al 2014 \\
\hline $\begin{array}{r}\text { Model(s), scope, scale, } \\
\text { approach }\end{array}$ & $\begin{array}{l}\text { Analyse distribution of } \\
\text { 'residual climate } \\
\text { responses' derived } \\
\text { from a HadCM3L } \\
\text { modelling ensemble. } \\
\text { Simulate by adjusting } \\
\text { solar irradiance. } \\
\text { Compare } 3 \text { weighting } \\
\text { schemes: by economic } \\
\text { output, population and } \\
\text { area. }\end{array}$ & $\begin{array}{l}\text { HadCM3L. Modify solar } \\
\text { irradiance directly, but } \\
\text { latitudinally and } \\
\text { seasonally to optimise } \\
\text { SRM at a grid-square } \\
\text { resolution. }\end{array}$ & $\begin{array}{l}\text { MPI ESM. } 5 \text { scenarios } \\
\text { ( } 3 \text { different forms of } \\
\text { SRM including solar } \\
\text { dimming and aerosol- } \\
\text { simulated SAI) } \\
\text { balancing transient } \\
\text { increases in climate } \\
\text { forcings. Report } \\
\text { results for continental } \\
\text { regions and } \\
\text { latitudinal zonal } \\
\text { means. }\end{array}$ & $\begin{array}{l}\text { GeoMIP ensemble of } 9 \\
\text { GCM models. Grid cell } \\
\text { analysis of broad global } \\
\text { regions in } 3 \text { simulations } \\
\text { (preindustrial, } 4 \times \mathrm{CO} 2 \\
\text { and } 4 \times \mathrm{CO} 2 \text { offset with } \\
\text { SRM). Modelling } \\
\text { adjusts solar irradiance. }\end{array}$ \\
\hline Key finding(s) / conclusion & $\begin{array}{l}\text { "A globally optimal } \\
\text { level of SRM can } \\
\text { compensate for a large } \\
\text { proportion of damages } \\
\text { at a regional level." } \\
\text { (p.661) "An SRM } \\
\text { scheme optimized for } \\
\text { population-weighted } \\
\text { regional precipitation } \\
\text { changes, however, } \\
\text { compensates for } 97 \% \\
\text { while compensating for } \\
70 \% \text { of population- } \\
\text { weighted temperature } \\
\text { changes." (p.661) }\end{array}$ & $\begin{array}{l}\text { "Spatial and temporal } \\
\text { variation in solar } \\
\text { insolation reduction can } \\
\text { be used to improve the } \\
\text { compensation between } \\
\text { the climate response due } \\
\text { to SRM and that due to } \\
\text { increased greenhouse } \\
\text { forcing. We do not ad- } \\
\text { dress how one might } \\
\text { achieve the desired } \\
\text { forcing distributions." } \\
\text { (p.367) }\end{array}$ & $\begin{array}{l}\text { Balancing the } \\
\text { transient forcing } \\
\text { appears reasonable, } \\
\text { but may be less } \\
\text { practical in reality. } \\
\text { Find that lowering of } \\
\text { precipitation in SAI } \\
\text { scenarios is about } \\
\text { double that in solar } \\
\text { insolation (space } \\
\text { mirror) scenarios. }\end{array}$ & $\begin{array}{l}\text { SRM maintains "a state } \\
\text { wherein the global and } \\
\text { annual mean surface } \\
\text { temperature is approx. } \\
\text { equal to that of [the } \\
\text { preindustrial climate, } \\
\text { but] complex regional } \\
\text { patterns of extreme } \\
\text { temperature and } \\
\text { precipitation persist." } \\
\text { (p.3918-19) Minimising } \\
\text { these would require } \\
\text { "manipulation of } \\
\text { forcings at a regional } \\
\text { scale." (p.3921) }\end{array}$ \\
\hline Choice of counterfactuals & $\begin{array}{l}\text { IPCC SRES A1B BAU } \\
(2 \times C O 2 \text { by } 2030)\end{array}$ & 2xCO2 climate & $\begin{array}{l}\text { RCP } 4.5 \text { by } 2100.650 \\
\text { ppm } C O 2\end{array}$ & 4xCO2 climate \\
\hline $\begin{array}{r}\text { Approach to uncertainties, } \\
\text { controllability \& } \\
\text { vulnerability }\end{array}$ & $\begin{array}{l}\text { Briefly discuss linearity, } \\
\text { aggregation, model } \\
\text { variability, and the ideal } \\
\text { nature of the SRM } \\
\text { intervention. Conclude } \\
\text { that the linear model } \\
\text { they use is applicable. } \\
\text { Vulnerability is } \\
\text { represented only } \\
\text { weakly in the weighting } \\
\text { scheme. }\end{array}$ & $\begin{array}{l}\text { No discussion of } \\
\text { controllability, despite } \\
\text { idealised nature of } \\
\text { model, nor of differential } \\
\text { vulnerability. Mention } \\
\text { model uncertainties such } \\
\text { as impacts of non- } \\
\text { linearity. }\end{array}$ & $\begin{array}{l}\text { Note technical, legal } \\
\text { and political } \\
\text { challenges, suggest } \\
\text { these make scenarios } \\
\text { less plausible than } \\
\text { the models imply. No } \\
\text { discussion of } \\
\text { vulnerability. }\end{array}$ & $\begin{array}{l}\text { Acknowledge } \\
\text { uncertainties in } \\
\text { simplified sensitivity } \\
\text { models used. Do not } \\
\text { discuss vulnerability, } \\
\text { nor controllability. }\end{array}$ \\
\hline Citations (as of Dec 2017) & 57 & 39 & 50 & 24 \\
\hline $\begin{array}{r}\text { SRM preferable to } \\
\text { unmitigated climate change }\end{array}$ & yes & yes & yes & yes \\
\hline $\begin{array}{l}\text { SAI 'corrects' temperature } \\
\text { better than precipitation }\end{array}$ & yes & yes & yes & yes \\
\hline $\begin{array}{l}\text { SRM has uneven } \\
\text { latitudinal effects }\end{array}$ & yes & yes & yes & yes \\
\hline $\begin{array}{l}\text { Limited SRM preferable to } \\
\text { full temp compensation }\end{array}$ & yes & yes & - & - \\
\hline $\begin{array}{r}\text { Regional modulation } \\
\text { desirable }\end{array}$ & - & yes & - & yes \\
\hline $\begin{array}{r}\text { Hemispheric SRM is } \\
\text { problematic }\end{array}$ & - & no & - & - \\
\hline $\begin{array}{r}\text { Considered weather } \\
\text { extremes }\end{array}$ & no & no & no & yes \\
\hline $\begin{array}{r}\text { Aerosol SAl less effective } \\
\text { than solar dimming }\end{array}$ & - & - & yes & - \\
\hline
\end{tabular}




\begin{tabular}{|c|c|c|c|}
\hline Paper & Kravitz et al 2014 & Ferraro et al 2014 & Yu et al 2015 \\
\hline $\begin{array}{r}\text { Model(s), scope, scale, } \\
\text { approach }\end{array}$ & $\begin{array}{l}\text { GeoMIP ensemble of } 12 \\
\text { GCM models, results } \\
\text { analysed for } 22 \text { macro- } \\
\text { regions in } 3 \text { simulations } \\
\text { (preindustrial, } 4 \times C O 2 \text { and } \\
4 \times C O 2 \text { offset with SRM). } \\
\text { Models adjust solar } \\
\text { irradiance. }\end{array}$ & $\begin{array}{l}\text { Reading IGCM, } 4 \text { scenarios: } \\
\text { control, } 4 \times C O 2 \text {, aerosol SAI } \\
\text { and solar dimming. Grid } \\
\text { based analysis of likelihood } \\
\text { of exceeding specified } \\
\text { climatic thresholds. }\end{array}$ & $\begin{array}{l}\text { GeoMIP ensemble of 7-13 } \\
\text { models, including both aerosol } \\
\text { SAI and solar irradiance } \\
\text { simulations. }\end{array}$ \\
\hline $\begin{array}{r}\text { Key finding(s) / } \\
\text { conclusion }\end{array}$ & $\begin{array}{l}\text { SRM that only partially } \\
\text { restored global mean } \\
\text { temperature to its } \\
\text { preindustrial level could } \\
\text { ameliorate both } \\
\text { anthropogenic temperature } \\
\text { and precipitation changes. } \\
\text { However, if precipitation } \\
\text { changes matter most, any } \\
\text { amount of SRM can } \\
\text { exacerbate impacts from } \\
\mathrm{CO}_{2} \text { forcings, for some } \\
\text { regions. }\end{array}$ & $\begin{array}{l}\text { Simulations based on solar } \\
\text { dimming underestimate } \\
\text { the risks from SAI. There is } \\
\text { substantial regional } \\
\text { variation in effectiveness of } \\
\text { geoengineering in } \\
\text { mitigating precipitation } \\
\text { changes, with over } 40 \% \text { of } \\
\text { the earth's surface } \\
\text { experiencing increased risk } \\
\text { of substantial precipitation } \\
\text { change under } 4 \mathrm{xCO}_{2}+\mathrm{SAl}\end{array}$ & $\begin{array}{l}\text { Large across-model variation in } \\
\text { the treatment of key } \\
\text { geoengineering processes and } \\
\text { the quantification of climate } \\
\text { damage creates significant } \\
\text { uncertainties in any strategies } \\
\text { to achieve optimal } \\
\text { compensation effectiveness } \\
\text { across different regions. }\end{array}$ \\
\hline Choice of counterfactuals & $4 \times \mathrm{CO}_{2}$ climate & $4 \times \mathrm{xOO}_{2}$ climate (1420ppm) & $4 \times \mathrm{CO}_{2}$ climate \\
\hline $\begin{array}{r}\text { Approach to } \\
\text { uncertainties, } \\
\text { controllability \& } \\
\text { vulnerability }\end{array}$ & $\begin{array}{l}\text { Acknowledge different } \\
\text { regional interests in } \\
\text { temperature and } \\
\text { precipitation changes. Do } \\
\text { not discuss controllability . } \\
\text { Discuss some modelling } \\
\text { uncertainties. }\end{array}$ & $\begin{array}{l}\text { Discuss factors affecting } \\
\text { regional variation and } \\
\text { relative vulnerability of } \\
\text { food producing areas to } \\
\text { climate changes. } \\
\text { Acknowledge the simplicity } \\
\text { and uncertainties } \\
\text { associated with the } \\
\text { modelling. Do not discuss } \\
\text { controllability. }\end{array}$ & $\begin{array}{l}\text { Note several remaining } \\
\text { uncertainties, and a need for } \\
\text { improved damage functions, } \\
\text { but suggest that 'ultimately' } \\
\text { such matters are 'beyond the } \\
\text { remit of the natural sciences'. } \\
\text { (p.21) Do not otherwise discuss } \\
\text { vulnerability, nor } \\
\text { seasonal/regional } \\
\text { controllability. }\end{array}$ \\
\hline Citations (as of Dec 2017) & 28 & 4 & 14 \\
\hline $\begin{array}{r}\text { SRM preferable to } \\
\text { unmitigated climate } \\
\text { change }\end{array}$ & yes & $?$ & yes \\
\hline $\begin{array}{l}\text { SAI 'corrects' temperature } \\
\text { better than precipitation }\end{array}$ & yes & yes & yes \\
\hline $\begin{array}{l}\text { SRM has uneven } \\
\text { latitudinal effects }\end{array}$ & yes & - & yes \\
\hline $\begin{array}{r}\text { Limited SRM preferable } \\
\text { to full temp } \\
\text { compensation }\end{array}$ & yes & - & ? \\
\hline $\begin{array}{r}\text { Regional modulation } \\
\text { desirable }\end{array}$ & ? & - & $?$ \\
\hline $\begin{array}{r}\text { Hemispheric SRM is } \\
\text { problematic }\end{array}$ & - & - & - \\
\hline $\begin{array}{r}\text { Considered weather } \\
\text { extremes }\end{array}$ & no & no & no \\
\hline $\begin{array}{r}\text { Aerosol SAl less effective } \\
\text { than solar dimming }\end{array}$ & $?$ & yes & yes \\
\hline
\end{tabular}


